\title{
HUBUNGAN ANTARA GENDER DAN KEPRIBADIAN DENGAN GAYA KEPEMIMPINAN DI PT MULTI CITRA ABADI MANADO
}

\author{
Eddy Madiono Sutanto \\ Dewi Mistyca Miliangan Liang \\ Universitas Kristen Petra \\ E-mail : dewim_11236@yahoo.com \\ Jalan Siwalankerto 121 - 131, Surabaya, 60236, Jawa Timur, Indonesia
}

\begin{abstract}
This study aims to find the relationship that exists between gender and personality as well as the supervisor leadership styles in PT Multi Citra Abadi Manado. The study is a quantitative research and uses questionnaire as data collection instrument. The population consists of 700 employees who work at PT Multi Citra Abadi Manado and the sample was 56 supervisors of PT Multi Citra Abadi Manado. The study used descriptive and statistical analysis. Descriptive analysis was done by using cross tabulation while the statistical analysis by using correlation analysis. Hypothesis test was done by using chi-square test and regression analysis. The result shows that there is a relationship between gender and personality, and it is also indicated that there is a relationship between gender and leadership style. The study shows the relationship between supervisor personality and leadership style in PT Multi Citra Abadi Manado. Based on the research, being open is considered a value of personality that should be increased for customers in global era.
\end{abstract}

Key words: Gender, Personality, Leadership Style, Leadership.

\begin{abstract}
ABSTRAK
Penelitian ini bertujuan untuk mengetahui hubungan yang terdapat antara gender dan kepribadian dengan gaya kepemimpinan supervisor di PT Multi Citra Abadi Manado. Jenis penelitian yang digunakan adalah penelitian kuantitatif dengan menggunakan teknik pengumpulan data berupa angket dan kuesioner. Populasi dalam penelitian ini adalah karyawan PT Multi Citra Abadi Manado yang berjumlah 700 orang dan sampel penelitian adalah supervisor PT Multi Citra Abadi Manado sebanyak 56 orang. Teknik analisis data yang digunakan adalah analisis deskriptif dan analisis statistik. Analisis deskriptif yang digunakan adalah tabulasi silang. Analisis statistik yang digunakan adalah analisa korelasi. Uji hipotesis dalam penelitian ini menggunakan uji chi-square dan analisis regresi. Hasilnya menunjukkan terdapat hubungan antara gender dengan kepribadian dan adanya hubungan antara gender dengan gaya kepemimpinan. Hasilnya juga menunjukkan terdapat hubungan antara kepribadian dengan gaya kepemimpinan supervisor di PT Multi Citra Abadi Manado. Berdasarkan hasil penelitian ini, disarankan untuk meningkatkan nilai dimensi openness kepribadian supervisor agar mampu memenuhi kebutuhan konsumen di era globalisasi saat ini.
\end{abstract}

Kata Kunci: Gender, Personality, Leadership Style, Leadership. 


\section{PENDAHULUAN}

Pada era global saat ini, wanita telah banyak memegang peranan penting dalam organisasi. Berdasarkan survei pada lembaga konsultasi global, $60 \%$ perusahaan terkemuka di Amerika memiliki setidaknya dua wanita yang memegang posisi penting sebagai komite eksekutif di perusahaan tersebut, delapan perusahaan - termasuk IBM, Pepsi Corporation dan General Motors- memiliki CEO wanita (McCullough 2014). Di Indonesia, salah satu contoh wanita yang memegang posisi penting dalam organisasi adalah Roosnianti Salihin yang merupakan Wakil Presiden Direktur Bank Panin (Bio 2014).

Konsep tentang karakteristik dan kepribadian yang ideal sebagai seorang pemimpin semakin mendapat perhatian dari banyak pihak. Sebagian besar pemimpin dunia yang sukses, seperti Richard Branson atau Pepsi Co Indra Nooyi harus bekerja keras untuk melatih dan mengelola kepribadian mereka dalam memimpin karyawan di perusahaan (Toegel dan Barzoux 2013). Hasil penelitian menyatakan bahwa wanita memiliki kualitas yang sama baiknya dengan pria. Kualitas manusia berpengaruh terhadap gaya kepemimpinan, dalam hal ini gaya kepemimpinan disesuaikan dengan kebutuhan organiasasi (Tantri, Margono, dan Muhammad 2011). Terdapat perbedaan pendekatan signifikan antara pria dan wanita dalam mengkomunikasikan maksud dan tujuan yang tercermin dalam gaya kepemimpinan (Kent dkk. 2010). Gaya kepemimpinan otokratis yang lebih mengutamakan penyelesaian tugas cenderung dimiliki oleh pria.

Pemimpin wanita umumnya cenderung memiliki gaya kepemimpinan demokratis, yang menggambarkan individu bermoral tinggi, dapat bekerja sama, mengutamakan mutu kerja dan dapat mengarahkan diri sendiri (Nuri dan Bhaskaroga 2012). Tipe kepribadian merupakan salah satu faktor yang mempengaruhi gaya kepemimpinan. Faktor fokus dalam kepemimpinan dipengaruhi oleh respon seseorang berkaitan dengan kepribadiannya. Seorang dengan kepribadian ekstrovert cenderung memiliki gaya kepe- mimpinan yang lebih efektif dalam memimpin jika dibandingkan orang berkepribadian introvert (Sieff dan Carstens 2006).

Gaya kepemimpinan yang tepat, sesuai dengan kepribadian individu dan kondisi perusahaan dibutuhkan oleh seorang pemimpin dalam rangka meningkatkan produktivitas dan efektivitas perusahaan. PT Multi Citra Abadi merupakan sebuah perusahaan retail modern yang berlokasi di Sulawesi Utara. PT Multi Citra Abadi atau yang dikenal dengan nama MultiMart pertama kali didirikan pada Desember 2004 di Manado, Sulawesi Utara. PT Multi Citra Abadi sampai pada tahun 2007 telah memiliki empat cabang yang terletak di Sulawesi Utara. Pada tahun 2014, PT Multi Citra Abadi telah memiliki tujuh cabang di Manado dari total keseluruhan 14 cabang di Sulawesi Utara.

Kesuksesan sebuah perusahaan tidak terlepas dari peran seorang pemimpin. Hal ini menjadi menarik untuk diteliti, bagaimana penerapan gaya kepemimpinan di perusahaan yang mampu berkembang dengan pesat dalam kurun waktu 10 tahun. Gaya kepemimpinan supervisor di PT Multi Citra Abadi Manado merupakan hal yang penting sehubungan dengan kemampuan untuk mengkomunikasikan informasi dan tugas dari atasan dan mengelola karyawan departemennya.

Berdasarkan fenomena yang ada yaitu kemampuan perusahaan untuk berkembang pesat sehubungan dengan peran pemimpin yakni supervisor, maka rumusan masalah dalam penelitian ini adalah apakah terdapat hubungan ketergantungan antara gender dan kepribadian dengan gaya kepemimpinan di PT Multi Citra Abadi Manado? Penelitian dilakukan dengan tujuan untuk mengetahui hubungan ketergantungan yang terdapat antara variabel gender dan kepribadian dengan gaya kepemimpinan di PT Multi Citra Abadi Manado.

\section{RERANGKA TEORITIS DAN HIPO-- TESIS \\ Gender \\ Gender adalah suatu konsep yang menunjuk} pada suatu sistem peranan dan hubungannya 
antara pria dan wanita yang tidak ditentukan oleh perbedaan biologi, akan tetapi ditentukan oleh lingkungan sosial, politik, dan ekonomi (Aida 2010, hal. 3). Gender merupakan suatu sifat yang melekat pada kaum laki-laki maupun perempuan yang dikonstruksikan secara sosial maupun kultural. Perubahan ciri dan sifat-sifat yang terjadi dari waktu ke waktu dan dari tempat ke tempat lainnya disebut konsep gender (Mansour 2006, hal. 71).

\section{Kepribadian}

Personality is the dynamic organization within the individual of those psychophysical systems that determine his unique adjustment to his environment" (kepribadian merupakan organisasi dinamis dalam diri individu tentang sistem psikofisik yang menentukan penyesuaian yang unik terhadap lingkungannya) (Pervine, Cervone, dan John 2005, hal. 225).The Big Five Theory oleh Goldberg (1981), Costa danMcCrae (1989) (dalam Pervine, Cervone, dan John 2005, hal. 232) membagi kepribadian ke dalam lima sifat yaitu neuroticism, extraversion, openness, agreeableness, dan conscientiousness.

Berdasarkan sifat kepribadian, terdapat beberapa dimensi sehubungan dengan teori The Big Five yang dinyatakan Pervine, Cervone, dan John (2005, hal. 264) yaitu reaksi terhadap suatu masalah, sikap saat berinteraksi, intensitas partisipasi terhadap kegiatan, reaksi terhadap hal-hal baru, cara menyelesaikan suatu pekerjaan, cara berbicara, melakukan tugas sesuai dengan peraturan dan standar, dan, melakukan kegiatan secara teratur.

\section{Gaya Kepemimpinan}

Menurut Sayuti, gaya kepemimpinan adalah suatu perwujudan tingkah laku dari seorang pemimpin yang menyangkut kemampuan dalam memimpin dan perwujudan tersebut biasanya membentuk suatu pola atau suatu bentuk tertentu (dalam Muhammad 2010, hal. 15).

Paul Hershey dan Ken Blanchard mengembangkan model kepemimpinan yang dikenal dengan istilah situational leadership theory. Situational leadership theory adalah teori kontingensi yang fokus pada kesiapan pengikut. Pada situational leadership theory terdapat empat gaya kepemimpinan (Robbins 2005, hal. 357) yaitu gaya kepemimpinan telling, selling, participating dan delegating. Menurut Robbins (2005, hal. 359) terdapat dua dimensi yang digunakan untuk mengetahui gaya kepemimpinan seseorang berdasarkan teori gaya kepemimpinan situasional yaitu unsur pengarahan dan dukungan kepada karyawan.

\section{Hubungan Antarvariabel dan Hipotesis Gender dengan Gaya Kepemimpinan}

Kemampuan berkembang sistem limbik otak wanita lebih baik jika dibandingkan dengan pria. (Rolls 2013). Reaksi seseorang terhadap suatu peristiwa akan membentuk suatu pola gaya kepemimpinan (Barbuto dkk. 2007). Berdasarkan penelitian sebelumnya, maka ditetapkan hipotesis satu sebagai berikut:

$\mathrm{H}_{1}$ : Terdapat hubungan ketergantungan antara gender dengan gaya kepemimpinan

\section{Gender dengan Kepribadian}

Pria umumnya identik dengan karakter masculine sedangkan wanita identik dengan karakter feminine. Perbedaan karakter ini akan membangun kepribadian seseorang yang berdampak pada gaya kepemimpinan (Agus 2008). Berdasarkan penelitian sebelumnya, maka ditetapkan hipotesis dua sebagai berikut:

$\mathrm{H}_{2}$ : Terdapat hubungan ketergantungan antara gender dengan kepribadian.

\section{Kepribadian dengan Gaya Kepemim- pinan}

Tipe kepribadian merupakan salah satu faktor yang mempengaruhi gaya kepemimpinan individu (Sudjiwanti 2010). Faktor fokus dalam kepemimpinan dipengaruhi oleh respon seseorang berkaitan dengan kepribadiannya (Sieff dan Carstens 2006). Berdasarkan penelitian sebelumnya maka ditetapkan hipotesis tiga sebagai berikut:

$\mathrm{H}_{3}$ : Terdapat hubungan ketergantungan antara kepribadian dengan gaya kepemimpinan. 


\section{Gender dan Kepribadian dengan Gaya Kepemimpinan}

Perbedaan karakter pria dan wanita akan membangun kepribadian seseorang (Agus 2008). Kepribadian seseorang akan berdampak pada respon yang diberikan ketika menghadapi situasi tertentu yang membentuk pola gaya kepemimpinan (Andersson, Dahlström, dan Ekvall 2006). Berdasarkan penelitian sebelumnya, maka ditetapkan hipotesis empat sebagai berikut:

$\mathrm{H}_{4}$ : Diduga terdapat hubungan ketergantungan antara gender dan kepribadian dengan gaya kepemimpinan. Secara skematis terlihat pada Gambar 1.

\section{METODE PENELITIAN Jenis Penelitian}

Jenis penelitian yang digunakan adalah penelitian kuantitatif dengan metode eksplanasi. Penelitian kuantitatif eksplanasi adalah penelitian yang bertujuan untuk menjelaskan, meringkas berbagai kondisi dan situasi yang timbul di masyarakat yang menjadi objek penelitian berdasarkan apa yang terjadi, lalu kemudian mengangkat ke permukaan karakter atau gambaran tentang kondisi dan situasi tersebut (Burhan 2005, hal. 73).

Penelitian ini menggunakan metode kuantitatif eksplanasi karena bertujuan untuk menjelaskan hubungan antar variabel yakni gender, kepribadian dan gaya kepemimpinan berdasarkan analisis statistik sehingga dapat menghasilkan generalisasi yang menjelaskan gambaran mengenai objek penelitian. Objek penelitian ini yaitu gender, kepribadian dan gaya kepemimpinan dan subyek penelitian adalah supervisor di PT Multi Citra Abadi Manado.

\section{Populasi dan Sampel Penelitian}

Populasi dalam penelitian ini adalah seluruh karyawan di PT Multi Citra Abadi Manado. Jumlah karyawan di PT Multi Citra Abadi Manado adalah sebanyak 700 orang. Penelitian ini menggunakan non-probability sampling dengan kriteria supervisor di PT Multi Citra Abadi Manado sejumlah 56 orang.

\section{Metode Pengumpulan Data}

Metode pengumpulan data dalam penelitian ini adalah dengan angket dan kuesioner penelitian. Angket adalah alat pengumpulan data yang digunakan dalam komunikasi tidak langsung untuk menghasilkan informasi tertentu lewat daftar pernyataan terperinci dan lengkap yang disampaikan kepada responden (Fathoni 2006: 92). Angket digunakan untuk memperoleh informasi sehubungan dengan variabel gender dan kepribadian supervisor.Kuesioner adalah suatu teknik komunikasi tidak langsung yang digunakan untuk memperoleh informasi lewat pertanyaan yang disampaikan kepada responden (Fathoni 2006, hal. 92). Kuesioner digunakan untuk mengetahui gaya kepemimpinan supervisor.

Definisi Operasional Variabel $\operatorname{Gender}\left(X_{1}\right)$ Gender merupakan konsep yang menunjuk pada suatu sistem peran dan hubungannya antara pria dan wanita yang tidak ditentukan oleh perbedaan biologi, akan tetapi ditentukan oleh lingkungan sosial, politik, dan ekonomi. Gender digolongkan menjadi dua yaitu pria dan wanita.

\section{Definisi Operasional Variabel Kepri- badian $\left(X_{2}\right)$}

Kepribadian adalah seperangkat karakter dinamis dan terorganisir yang dimiliki oleh individu, secara khas mempengaruhi kognisi, motivasi dan perilaku seseorang pada berbagai situasi. Pengukuran pada variabel kepribadian menggunakan tes MMPI (Minnesota Multiphasic Personality Inventory). Dimensi kepribadian yang digunakan dalam penelitian ini yakni individu yang mudah gugup, mengalami kecemasan, mudah tertekan, merasa rendah diri, canggung berada diantara banyak orang memiliki nilai dimensi neuroticism kepribadian yang dominan.

Individu yang memiliki pendirian yang teguh, berusaha memperbaiki kesalahan, optimis, mengambil inisiatif untuk menyapa orang asing, nyaman berinteraksi dengan banyak orang, memiliki kegiatan sosial di 


\section{Gambar 1 \\ Rerangka Pemikiran}

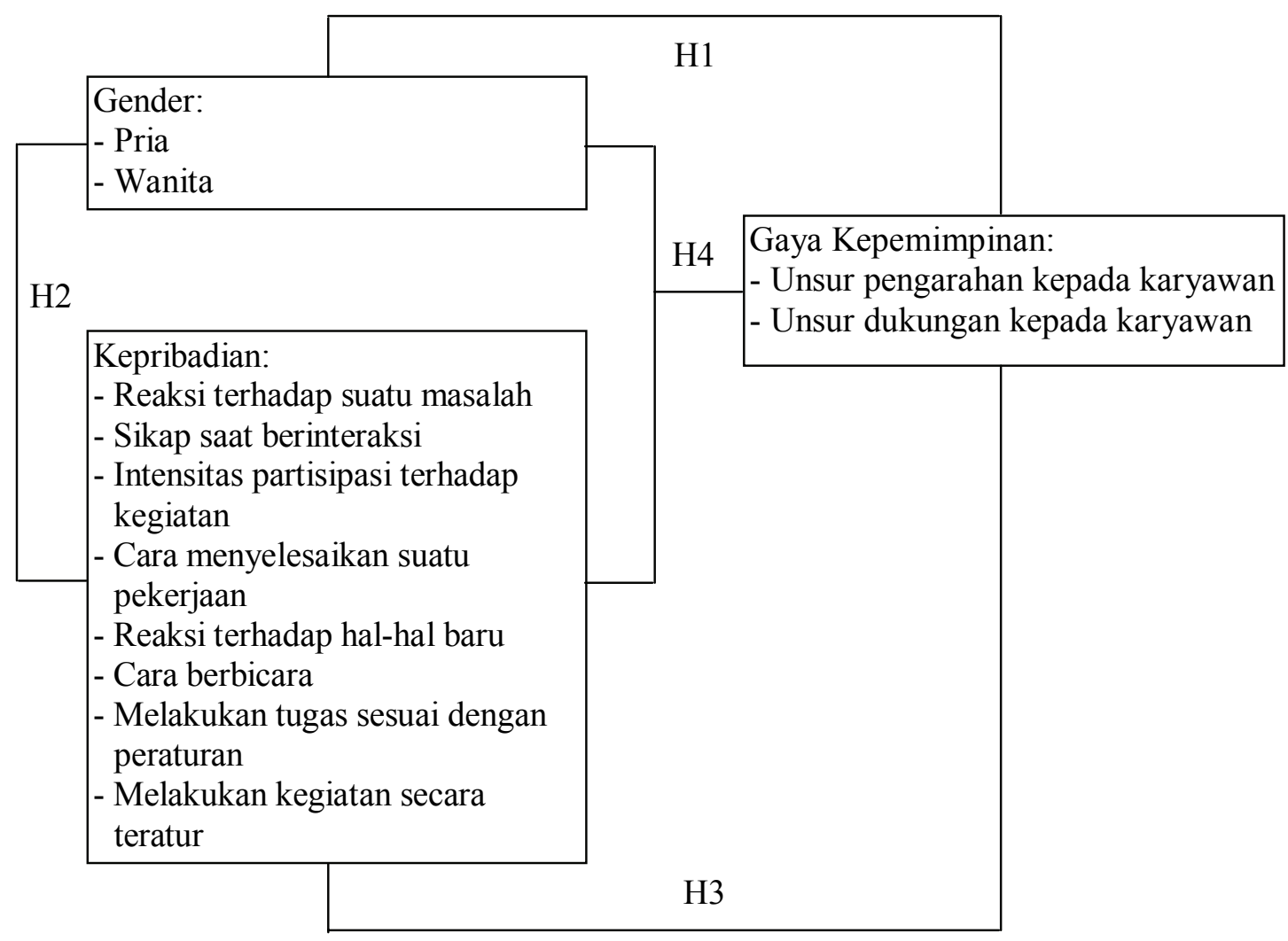

Sumber: Aida (2010); Pervine, Cervone, dan John (2005); dan Robbins (2005).

luar lingkungan pekerjaan, dan menyukai tantangan mempunyai nilai dimensi extraversion kepribadian yang dominan. Individu yang mengemukakan perasaannya ketika menghadapi suatu masalah, bersemangat mencoba hal-hal baru, memiliki ide-ide unik dan menggunakan imajinasi dalam menyelesaikan pekerjaan mempunyai nilai dimensi openness kepribadian yang dominan. Individu yang mudah mempercayai orang lain, mendelegasikan tugas dan wewenang pengambilan keputusan kepada karyawan, jujur, apa adanya, bersimpati dan empati kepada sesama memiliki nilai dimensi agreeableness kepribadian yang dominan. Individu yang teratur, taat pada peraturan perusahaan, menyelesaikan pekerjaan sesuai bahkan diatas standar yang ditetapkan, menyelesaikan tugas lebih cepat, melihat peluang dan resiko dari tindakan yang diambil memiliki nilai dimensi conscientiousness kepribadian yang dominan.

\section{Definisi Operasional Variabel Gaya Ke-} pemimpinan $(Y)$

Menurut Sayuti, gaya kepemimpinan adalah perwujudan tingkah laku pemimpin yang berhubungan dengan kemampuannya dalam memimpin dan perwujudan tersebut biasanya membentuk suatu pola atau suatu bentuk tertentu. Dimensi gaya kepemimpinan dalam penelitian ini yakni pemimpin mengawasi, menentukan apa yang ingin dicapai dan harus dilakukan oleh karyawan serta fokus pada penyelesaian tugas dapat dikelompokan ke dalam gaya kepemimpinan telling.

Pemimpin menjelaskan tujuan yang ingin dicapai, bekerja sama, dan melibatkan karyawan melalui ide-ide dan saran serta fokus pada penyelesaian tugas dan hubungan kerjadapat dikelompokan ke dalam gaya kepemimpinan selling. Pemimpin membantu karyawan menentukan kegiatan yang harus dilakukan, mendiskusikan masalah dan mendukung karyawan untuk menemukan solusi 
Tabel 1

Uji Kesahihan Dimensi Neuroticism

\begin{tabular}{lc}
\hline \multicolumn{1}{c}{ Item } & $\boldsymbol{r}$ hitung \\
\hline Anxiety 1 & 0,322 \\
Anxiety 2 & 0,398 \\
Hostility & 0,439 \\
Depression 1 & 0,708 \\
Depression 2 & 0,633 \\
Self-consciousness & 0,394 \\
Impulsiveness 1 & 0,458 \\
Impulsiveness 2 & 0,396 \\
Vulnerability 1 & 0,727 \\
Vulnerability 2 & 0,589 \\
\hline
\end{tabular}

Sumber: Data Primer Diolah.

Tabel 2

Uji Kesahihan Dimensi Extraversion

\begin{tabular}{lc}
\hline \multicolumn{1}{c}{ Item } & $\boldsymbol{r}$ hitung \\
\hline Warmth 1 & 0,401 \\
Warmth 2 & 0,444 \\
Gregariousness 1 & 0,645 \\
Gregariousness 2 & 0,386 \\
Gregariousness 3 & 0,416 \\
Assertiveness & 0,381 \\
Activity & 0,338 \\
Excitement seeking & 0,452 \\
Positive Emotion 1 & 0,368 \\
Positive Emotion 2 & 0,475 \\
\hline
\end{tabular}

Sumber: Data Primer Diolah.

Tabel 3

Uji Kesahihan Dimensi Openness

\begin{tabular}{lc}
\hline \multicolumn{1}{c}{ Item } & $\boldsymbol{r}$ hitung \\
\hline Fantasy 1 & 0,409 \\
Fantasy 2 & 0,468 \\
Aesthetic 1 & 0,486 \\
Aesthetic 2 & 0,425 \\
Feelings & 0,390 \\
Action & 0,496 \\
Ideas 1 & 0,525 \\
Ideas 2 & 0,467 \\
Values 1 & 0,357 \\
Values 2 & 0,360 \\
\hline
\end{tabular}

Sumber: Data Primer Diolah.

dan fokus pada hubungan kerja dapat dikelompokan ke dalam gaya kepemimpinan participating. Pemimpin memberikan kebebasan anggota kelompok memutuskan sendiri apa yang akan mereka lakukan tanpa adanya pengarahan,tidak fokus pada penye-
Tabel 4

Uji Kesahihan Dimensi Agreeableness

\begin{tabular}{lc}
\hline \multicolumn{1}{c}{ Item } & $\boldsymbol{r}$ hitung \\
\hline Trust 1 & 0,692 \\
Trust 2 & 0,359 \\
Straightfowardness 1 & 0,397 \\
Straightfowardness 2 & 0,404 \\
Alturism 1 & 0,647 \\
Alturism 2 & 0,708 \\
Compliance & 0,378 \\
Modesty & 0,408 \\
Tender mindedness 1 & 0,383 \\
Tender mindedness 2 & 0,723 \\
\hline Sund Data Priner Didn
\end{tabular}

Sumber: Data Primer Diolah.

Tabel 5

Uji Kesahihan Dimensi Conscientiousness

\begin{tabular}{lc}
\hline \multicolumn{1}{c}{ Item } & $\boldsymbol{r}$ hitung \\
\hline Competence & 0,344 \\
Order & 0,488 \\
Dutifulness 1 & 0,405 \\
Dutifulness 2 & 0,347 \\
Achievement-striving 1 & 0,568 \\
Achievement-striving 2 & 0,557 \\
Self-discipline 1 & 0,362 \\
Self-discipline 2 & 0,458 \\
Deliberation 1 & 0,641 \\
Deliberation 2 & 0,485
\end{tabular}

Sumber: Data Primer Diolah.

Tabel 6

Uji Kesahihan Gaya Kepemimpinan

\begin{tabular}{lc}
\hline Item & $\boldsymbol{r}$ hitung \\
\hline Gaya Kepemimpinan 1 & 0,664 \\
Gaya Kepemimpinan 2 & 0,667 \\
Gaya Kepemimpinan 3 & 0,575 \\
Gaya Kepemimpinan 4 & 0,409 \\
Gaya Kepemimpinan 5 & 0,609 \\
Gaya Kepemimpinan 6 & 0,418 \\
Gaya Kepemimpinan 7 & 0,591 \\
Gaya Kepemimpinan 8 & 0,472 \\
Gaya Kepemimpinan 9 & 0,582 \\
Gaya Kepemimpinan 10 & 0,470 \\
\hline
\end{tabular}

Sumber: Data Primer Diolah.

lesaian tugas maupun hubungan kerja dapat dikelompokan ke dalam gaya kepemimpinan delegating.

\section{Teknik Pengolahan Data}

Teknik pengolahan data dalam penelitian ini 
Tabel 7

Uji Keterandalan Variabel Penelitian

\begin{tabular}{lc}
\hline \multicolumn{1}{c}{ Variabel } & Nilai $\boldsymbol{r}$ \\
\hline Kepribadian Dimensi Neuroticsim & 0,666 \\
Kepribadian Dimensi Extraversion & 0,615 \\
Kepribadian Dimensi Openess & 0,622 \\
Kepribadian Dimensi Agreeableness & 0,829 \\
Kepribadian Dimensi Conscientiousness & 0,781 \\
Gaya Kepemimpinan & 0,811 \\
\hline
\end{tabular}

Sumber: Data Primer Diolah.

menggunakan uji kesahihan dan uji keterandalan. Uji kesahihan dilakukan untuk mengetahui seberapa jauh instrumen penelitian mampu mencerminkan isi yang sesuai dengan hal dan sifat yang diukur. Uji keterandalan digunakan untuk mengukur konsistensi jawaban yang diberikan responden dari waktu ke waktu.

\section{Teknik Analisis Data}

Teknik analisis data dalam penelitian ini adalah analisis deskriptif dan analisis korelasi. Analisis deskriptif dilakukan padavariabel penelitian yaitu kepribadian dan gaya kepemimpinan. Analisis deskriptif dilakukan dengan menjumlahkan nilai respon setiap tipe yang terdapat pada angket. Hasil penjumlahan kemudian dibandingkan untuk setiap tipe nilai kepribadianmaupun gaya kepemimpinan guna menentukan tipe yang dominan.Analisis korelasi dilakukan dengan tabulasi silang antar variabel penelitian.

\section{Uji Hipotesis}

Uji hipotesis dalam penelitian ini dilakukan dengan menggunakan uji chi-square dan analisis regresi. Uji chi-square dilakukan untuk mengetahui hubungan yang terdapat antara variabel penelitian.Analisis Regresi dilakukan untuk mengetahui hubungan yang terdapat pada keseluruhan variabel penelitian.

\section{ANALISIS DATA DAN PEMBAHASAN Uji Kesahihan}

Suatu item pernyataan dan pertanyaan dapat dikatakan sahih jika corrected total item correlation memiliki nilai $r \geq 0,30$. Berdasarkan Tabel 1 (dimensi neuroticism), Tabel 2 (dimensi extraversion), Tabel 3 (di mensi openness), Tabel 4 (dimensi agreeableness), dan Tabel 5 (dimensi conscientiousness) maka pernyataan-pernyataan pada angket kepribadian dapat dinyatakan sahih. Berdasarkan pada Tabel 6, maka pertanyaan-pertanyaan pada kuesioner untuk mengukur kesahihan variabel penelitian gaya kepemimpinan dapat dinyatakan sahih. Berdasarkan hasil uji kesahihan maka itemitem yang digunakan untuk mengukur variabel penelitian dapat dinyatakan sahih,

\section{Uji Keterandalan}

Suatu item pernyataan dan pertanyaan dapat dikatakan handal jika koefisien split half Spearman-Brown memiliki nilai $r>0,60$. Berdasarkan Tabel 7 maka pernyataan pada angket kepribadian dan pertanyaan pada kuesioner gaya kepemimpinan dapat dinyatakan handal.

\section{Analisis Deskriptif}

Berdasarkan Tabel 8 Supervisor pada PT Multi Citra Abadi Manado berjumlah 56 orang yang terdiri dari 31 orang pria dan 25 orang wanita.

Berdasarkan Tabel 9 supervisor PT Multi Citra Abadi Manado umumnya memiliki dimensi conscientiousness yang dominan yaitu sebesar $41,1 \%$ yang mewakili 23 orang dari total keseluruhan supervisor yaitu sebanyak 56 orang.

Berdasarkan Tabel 10 supervisor PT Multi Citra Abadi Manado umumnya memiliki gaya kepemimpinan participating yang dominan yaitu sebesar $32,1 \%$ yang mewakili 18 orang dari total keseluruhan supervisor yaitu sebanyak 56 orang. Gaya kepemimpinan telling juga dominan, yang mewakili 16 
Tabel 8

Analisis Deskriptif Variabel Gender

\begin{tabular}{llr}
\hline \multicolumn{1}{c}{ Gender } & Jumlah & \% dari Total \\
\hline Pria & 31 orang & $55,4 \%$ \\
Wanita & 25 orang & $44,6 \%$ \\
Total & 56 orang & $100 \%$ \\
\hline
\end{tabular}

Sumber: Data Primer Diolah.

Tabel 9

Analisis Deskriptif Variabel Kepribadian

\begin{tabular}{lrr}
\hline $\begin{array}{c}\text { Dimensi } \\
\text { Kepribadian }\end{array}$ & Frekuensi & $\begin{array}{c}\text { \% dari } \\
\text { Total }\end{array}$ \\
\hline Neuroticism & 4 & $7,1 \%$ \\
Extraversion & 15 & $26,8 \%$ \\
Openness & 5 & $8,9 \%$ \\
Agreeableness & 9 & $16,1 \%$ \\
Conscientiousness & 23 & $41,1 \%$ \\
Total & 56 & $100 \%$ \\
\hline
\end{tabular}

Sumber: Data Primer Diolah.

Tabel 10

Analisis Deskriptif Variabel Gaya Kepemimpinan

\begin{tabular}{lrc}
\hline $\begin{array}{c}\text { Gaya } \\
\text { Kepemimpinan }\end{array}$ & Frekuensi & $\begin{array}{c}\text { \% dari } \\
\text { Total }\end{array}$ \\
\hline Telling & 16 & $28,6 \%$ \\
Selling & 13 & $23,2 \%$ \\
Participating & 18 & $32,1 \%$ \\
Delegating & 9 & $16,1 \%$ \\
Total & 56 & $100 \%$ \\
\hline
\end{tabular}

Sumber: Data Primer Diolah.

orang dengan persentase sebesar $28,6 \%$.

\section{Analisis Korelasi}

Berdasarkan analisis korelasi pada Tabel 11, supervisor pria di PT Multi Citra Abadi Manado umumnya memiliki gaya kepemimpinan telling dengan persentase sebesar $28,6 \%$ yang berarti supervisor pria cenderung untuk mengawasi, mengarahkan dan menentukan hal-hal yang harus dilakukan dalam mencapai tujuan perusahaan dengan kurang memperhatikan unsur dukungan kepada karyawan. Supervisor wanita dengan persentase sebesar 23,2\% cenderung memiliki gaya kepemimpinan participating yang berarti selalu mengutamakan hubungan kerja dengan karyawan yang dipimpinnya, selalu mendukung dan memotivasi karyawan.
Berdasarkan analisis korelasi pada Tabel 12 , supervisor pria cenderung memiliki nilai dimensi conscientiousness kepribadian yang lebih tinggi yaitu sebesar 39,3\% jika dibandingkan dengan supervisor wanita sebesar $1,8 \%$. Nilai dimensi conscientiousness kepribadian yang tinggi menunjukkan bahwa supervisor pria memiliki dorongan memperoleh pencapaian, selalu berusaha untuk menyelesaikan tugas tepat waktu dan sesuai dengan standar yang diminta. Di samping itu mereka menjalankan tugas sesuai dengan ketentuanketentuan yang berlaku di perusahaan serta cenderung teratur dan ambisius. Supervisor wanita memiliki nilai dimensi agreeableness kepribadian yang lebih tinggi yaitu sebesar $16,1 \%$ jika dibandingkan dengan supervisor pria sebesar $0 \%$. Hal ini mencerminkan kepribadian supervisor wanita yang cenderung suka mengalah, menghindari konflik, pemaaf dan suka membantu karyawan yang dipimpinnya

Berdasarkan analisis korelasi pada Tabel 13, supervisor di PT Multi Citra Abadi Manado memiliki nilai dimensi conscitiousness kepribadian yang dominandengan gaya kepemimpinan telling yaitu sebanyak 12 orang dengan persentase sebesar 21,4\%. Supervisor dengan nilai dimensi extraversion kepribadian yang dominan dan cenderung memiliki gaya kepemimpinan participating sebanyak 8 orang atau sebesar $14,3 \%$. Supervisor dengan nilai dimensi agreeableness kepribadian yang dominan dan cenderung memiliki gaya kepemimpinan participating sebanyak 5 orang atau sebesar $8,9 \%$ serta supervisor dengan nilai dimensi neuroticism kepribadian yang dominan dan cenderung memiliki gaya kepemimpinan selling sebanyak 3 orang atau sebesar 5,4\%. Supervisor dengan nilai dimensi openness kepribadian yang dominan dan memiliki gaya kepemimpinan selling sebanyak 2 orang dengan persentase sebesar 3,6\% sama banyaknya dengan supervisor yang memiliki gaya kepemimpinan participating.

\section{Uji Hipotesis}

\section{Uji Chi-Square}

Uji chi-square dilakukan pada variabel gender, kepribadian, dan gaya kepemimpinan 
Tabel 11

Cross Tabulasi Silang Gender dengan Gaya Kepemimpinan

\begin{tabular}{llrrrrr}
\hline & \multirow{2}{*}{ Gender } & \multicolumn{6}{c}{ Gaya Kepemimpinan } & \multirow{2}{*}{ Total } \\
\cline { 2 - 6 } & & Telling & \multicolumn{1}{c}{ Selling } & Participating & Delegating & \\
\hline Pria & Frekuensi & 16 & 4 & 5 & 6 & 31 \\
\multirow{3}{*}{ Wanita } & $\%$ dari Total & $28,6 \%$ & $7,1 \%$ & $8,9 \%$ & $10,7 \%$ & $55,4 \%$ \\
& Frekuensi & 0 & 9 & 13 & 3 & 25 \\
\multirow{2}{*}{ Total } & $\%$ dari Total & $0 \%$ & $16,1 \%$ & $23,2 \%$ & $5,4 \%$ & $44,6 \%$ \\
& Frekuensi & 16 & 13 & 18 & 9 & 56 \\
& \% dari Total & $28,6 \%$ & $23,2 \%$ & $32,1 \%$ & $16,1 \%$ & $100 \%$ \\
\hline
\end{tabular}

Sumber: Data Primer Diolah.

Tabel 12

Cross Tabulasi Silang Gender dengan Kepribadian

\begin{tabular}{|c|c|c|c|c|c|c|c|}
\hline & \multirow[b]{2}{*}{ Gender } & \multicolumn{5}{|c|}{ Kepribadian } & \multirow[t]{2}{*}{ Total } \\
\hline & & $\begin{array}{c}\text { Neurot } \\
\text { icism }\end{array}$ & $\begin{array}{c}\text { Extraver } \\
\text { sion }\end{array}$ & $\begin{array}{c}\text { Openn } \\
\text { ess }\end{array}$ & $\begin{array}{c}\text { Agreeable } \\
\text { ness }\end{array}$ & $\begin{array}{c}\text { Conscient } \\
\text { iousness }\end{array}$ & \\
\hline Pria & $\begin{array}{l}\text { Frekuensi } \\
\% \text { dari Total }\end{array}$ & $\begin{array}{r}0 \\
0 \%\end{array}$ & $\begin{array}{r}7 \\
12,5 \%\end{array}$ & $\begin{array}{r}2 \\
3,6 \%\end{array}$ & $\begin{array}{r}0 \\
0 \%\end{array}$ & $\begin{array}{r}22 \\
39,3 \%\end{array}$ & $\begin{array}{r}31 \\
55,4 \%\end{array}$ \\
\hline Wanita & $\begin{array}{l}\text { Frekuensi } \\
\% \text { dari Total }\end{array}$ & $\begin{array}{r}4 \\
7,1 \%\end{array}$ & $\begin{array}{r}8 \\
14,3 \%\end{array}$ & $\begin{array}{r}3 \\
5,4 \%\end{array}$ & $\begin{array}{r}9 \\
16,1 \%\end{array}$ & $\begin{array}{r}1 \\
1,8 \%\end{array}$ & $\begin{array}{r}25 \\
44,6 \%\end{array}$ \\
\hline Total & $\begin{array}{l}\text { Frekuensi } \\
\% \text { dari Total }\end{array}$ & $\begin{array}{r}4 \\
7,1 \%\end{array}$ & $\begin{array}{r}15 \\
26,8 \%\end{array}$ & $\begin{array}{r}5 \\
8,9 \%\end{array}$ & $\begin{array}{r}9 \\
16,1 \%\end{array}$ & $\begin{array}{r}23 \\
41,1 \%\end{array}$ & $\begin{array}{r}56 \\
100 \%\end{array}$ \\
\hline
\end{tabular}

Sumber: Data Primer Diolah.

untuk mengetahui hubungan yang terdapat di antara variabel-variabel. Berdasarkan Tabel 14, maka hasil uji hipotesis untuk variabel penelitian yakni nilai signifikansi hasil uji chi-square variabel gender dengan gaya kepemimpinan adalah 0,000 . Nilai signifikansi yaitu $0,000<0,05$ maka $H_{l}$ diterima bahwa terdapat hubungan ketergantungan antara variabel gender dengan gaya kepemimpinan. Nilai signifikansi hasil uji chisquare variabel gender dengan kepribadian adalah 0,000 . Nilai signifikansi yaitu 0,000 $<0,05$ maka $H_{l}$ diterima bahwa terdapat hubungan ketergantungan antara variabel gender dengan kepribadian. Nilai signifikansi hasil uji chi-square variabel kepribadian dengan gaya kepemimpinan adalah 0,004 Nilai signifikansi yaitu $0,004<0,05$ maka terdapat hubungan ketergantungan antara kepribadian dengan gaya kepemimpinan.

\section{Analisis Regresi}

Analisis regresi pada Tabel 15 dilakukan dengan uji $\mathrm{F}$ untuk mengetahui hubungan antara variabel gender dan kepribadian den- gan gaya kepemimpinan. Nilai signifikansi hasil uji $\mathrm{F}$ variabel gender dan kepribadian dengan gaya kepemimpinan adalah sebesar 0,035 . Berdasarkan pada nilai signifikansi hasil uji $\mathrm{F}$ yaitu $0,035<0,05$ maka terdapat hubungan antara variabel gender dan kepribadian yang secara simultan dan signifikan mempengaruhi variabel gaya kepemimpinan.

\section{Pembahasan}

Berdasarkan hasil penelitian, supervisor pria dengan nilai dimensi conscientiousness kepribadian yang dominan cenderung memiliki gaya kepemimpinan telling. Nilai dimensi conscientiousness kepribadian berhubungan dengan supervisor pria yang cenderung teratur, berorientasi pada suatu pencapaian, penyelesaian tugas, ambisi dan kontrol terhadap lingkungan sosial. Pernyataan tersebut didukung dengan hasil penelitian sebelumnya yang menyatakan bahwa nilai dimensi conscientiousness kepribadian merupakan nilai yang paling dominan dari kepribadian pria dalam teori kepribadian The Big Five (Schwartz dan Rubel 2005). Nilai dimensi 
Tabel 13

Cross Tabulasi Silang Kepribadian dengan Gaya Kepemimpinan

\begin{tabular}{|c|c|c|c|c|c|c|}
\hline \multirow{2}{*}{\multicolumn{2}{|c|}{ Kepribadian }} & \multicolumn{4}{|c|}{ Gaya Kepemimpinan } & \multirow{2}{*}{ Total } \\
\hline & & Telling & Selling & Participating & Delegating & \\
\hline \multirow{2}{*}{ Neuroticism } & Frekuensi & 0 & 3 & 0 & 1 & 4 \\
\hline & $\%$ dari Total & $0 \%$ & $5,4 \%$ & $0 \%$ & $1,8 \%$ & $7,1 \%$ \\
\hline \multirow{4}{*}{$\begin{array}{l}\text { Extraver } \\
\text { sion } \\
\text { Openness }\end{array}$} & Frekuensi & 4 & 1 & 8 & 2 & 15 \\
\hline & $\%$ dari Total & $7,1 \%$ & $1,8 \%$ & $14,3 \%$ & $3,6 \%$ & $26,8 \%$ \\
\hline & Frekuensi & 0 & 2 & 2 & 1 & 5 \\
\hline & $\%$ dari Total & $0 \%$ & $3,6 \%$ & $3,6 \%$ & $1,8 \%$ & $8,9 \%$ \\
\hline \multirow{6}{*}{$\begin{array}{l}\text { Agree } \\
\text { ableness } \\
\text { Conscien } \\
\text { tiousness } \\
\text { Total }\end{array}$} & Frekuensi & 0 & 4 & 5 & 0 & 9 \\
\hline & $\%$ dari Total & $0 \%$ & $7,1 \%$ & $8,9 \%$ & $0 \%$ & $16,1 \%$ \\
\hline & Frekuensi & 12 & 3 & 3 & 5 & 23 \\
\hline & $\%$ dari Total & $21,4 \%$ & $5,4 \%$ & $5,4 \%$ & $8,9 \%$ & $41,1 \%$ \\
\hline & Frekuensi & 16 & 13 & 18 & 9 & 56 \\
\hline & $\%$ dari Total & $28,6 \%$ & $23,2 \%$ & $32,1 \%$ & $16,1 \%$ & $100 \%$ \\
\hline
\end{tabular}

Sumber: Data Primer Diolah.

Tabel 14

Signifikansi Uji Chi-Square Variabel Penelitian

\begin{tabular}{lccc}
\hline & Gender & Kepribadian & Gaya Kepemimpinan \\
\hline Gender & - & 0,000 & 0,000 \\
Kepribadian & 0,000 & - & 0,004 \\
Gaya Kepemimpinan & 0,000 & 0,004 & - \\
\hline
\end{tabular}

Sumber: Data Primer Diolah.

Tabel 15

Analisis Regresi

\begin{tabular}{lc}
\hline Model & Sig. \\
\hline Regression & 0,035 \\
\hline
\end{tabular}

conscientiousness kepribadian berhubungan dengan gaya kepemimpinan telling yang cenderung memiliki fokus tinggi pada pekerjaan tetapi kurang memperhatikan unsur hubungan dengan rekan kerja.

Pernyataan di atas didukung dengan hasil penelitian sebelumnya yang menyebutkan bahwa pria memiliki gaya kepemimpinan yang lebih berorientasi pada penyelesaian tugas dengan atribut-atribut yang mendukung seperti struktur, transaksional, autokratik, pemberi instruksi serta berorientasi pada bisnis (Barbuto dkk. 2007). Hasil penelitian ini juga mendukung pernyataan bahwa pria lebih cenderung memiliki gaya kepemimpinan yang mengutamakan kontrol dan penyelesaian tugas (Nuri dan Bhaskaroga 2012).

Hasil penelitian juga menunjukkan bahwa supervisor wanita dengan nilai dimensi agreeableness kepribadian yang dominan cenderung memiliki gaya kepemimpinan participating. Nilai dimensi agreeableness kepribadian berhubungan dengan kepribadian supervisor wanita yang lebih berorientasi pada hubungan sosial, memelihara hubungan yang baik dengan karyawan yang dipimpinnya. Pernyataan ini didukung dengan hasil penelitian sebelumnya yang menyebutkan bahwa wanita lebih termotivasi untuk mempertahankan hubungan sosial dengan melakukan tindakan-tindakan yang sifatnya menyenangkan (Weisberg, DeYoung, dan Hirsh 2011). Pernyataan ini juga didukung hasil penelitian sebelumnya yang menyebutkan bahwa wanita umumnya memiliki nilai yang lebih pada dimensi agreeableness kepribadian, jika dibandingkan pada pria (Lehmann dkk. 2013).

Pada supervisor wanita nilai dimensi agreeableness kepribadian yang dominan 
juga berhubungan dengan gaya kepemimpinan participating yang cenderung memberi motivasi pada karyawan dan mengutamakan hubungan baik dengan karyawan yang dipimpinnya. Pernyataan ini didukung dengan hasil penelitian sebelumnya yang menyebutkan bahwa wanita memiliki gaya kepemimpinan yang mengutamakan pemeliharaan hubungan sosial dengan atribut-atribut pendukung seperti pertimbangan, transformasional, partisipatif, memiliki ketertarikan untuk bersosialisasi dan berorientasi pada manusia (Garcia dkk. 2014).

Hasil penelitian sesuai dengan penelitian sebelumnya yang menyebutkan bahwa pemimpin wanita cenderung memiliki gaya kepemimpinan dengan menggunakkan pendekatan emosional, mengutamakan kerja sama tim sebagai seorang individu bermoral tinggi (Nuri dan Bhaskaroga 2012). Wanita memiliki gaya kepemimpinan yang lebih partisipatif dan demokratis jika dibandingkan pada pria (Snaebjornsson dan Edvardsson 2012). Pemimpin wanita cenderung memberikan motivasi positif kepada karyawan baik secara moral maupun penghargaan melalui insentif. (Barbuto dkk. 2007).Wanita lebih menekankan pada nilai-nilai sosial dan kebajikan ketika memimpin sebuah organisasi (Schwartz dan Rubel 2005). Berdasarkan hasil penelitian, maka dapat dinyatakan terdapat hubungan antara variabel gender dan kepribadian dengan gaya kepemimpinan.

\section{SIMPULAN, IMPLIKASI, SARAN, DAN KETERBATASAN}

Hasil penelitian menunjukan terdapat hubungan ketergantungan antara variabel gender, kepribadian dan gaya kepemimpinan. Penelitian ini dapat memberikan implikasi manajerial yakni dengan melakukan penelitian lebih lanjut tentang variabel tingkat kesiapan pekerja. Teori gaya kepemimpinan situational Hershey dan Blanchard yang digunakan dalam penelitian menyatakan hubungan gaya kepemimpinan dengan tingkat kesiapan pekerja (Robbins 2005, hal. 359).

Gaya kepemimpinan memiliki pengaruh yang signifikan terhadap kinerja karyawan
(Obiwuru, Okwu, Akpa, dan Nwankwere 2011). Penambahan variabel tingkat kesiapan pekerja pada penelitian selanjutnya dapat membantu perusahaan untuk menentukan gaya kepemimpinan yang paling sesuai dengan tingkat kesiapan pekerja dalam rangka meningkatkan kinerja karyawan dan produktivitas perusahaan.

Keterbatasan penelitian ini yakni ketidakmampuan untuk melakukan penelitian di seluruh cabang perusahaan yang terletak di luar daerah Manado seperti Maluku Utara. Saran berdasarkan penelitian ini adalah gaya kepemimpinan supervisor sebaiknya juga memperhatikan penyelesaian tugas dan usaha untuk meningkatkan nilai dimensi openness kepribadian supervisor.

\section{DAFTAR RUJUKAN}

Agus, S 2008, 'Pembentukan karakter olah ragawan ditinjau dari perbedaan gender, peran serta orang tua, guru, pelatih olahraga, dan keikutsertaan dalam aktivitas olahraga serta jenis olah raganya', Universitas Negeri Yogyakarta, Journal of Personality, 1 (1), 1-22.

Aida, V 2010, Pemberdayaan perempuan dari masa ke masa, Bogor: IPB Pres.

Andersson, AL, Dahlström, B dan Ekvall, G 2006, 'Leadership style and managerial type as related to working climate, gender and personality in terms of the spiral aftereffect technique' Journal of Applied Psychology, 1 (1), 1-16.

Barbuto, JE, dkk. 2007, 'Effect of gender, education, and age upon leader use of influence tatics and full range leadership behaviors', Journal of Agricultural Leadership, 1(56), 71-83.

Bio, GB 2014, 'Wakil presdir panin roosnianti salihin bicara karir dan keluarga', Liputan6, 11 Juni, Diakses 17 Oktober 2014, $\quad<$ http://lifesty le.liputan6.com/read/2061010/wakilpresdir-panin-roosniati-salihin-bicarakarir-dan-keluarga>.

Burhan, B 2005, Metodologi penelitian kuantitatif komunikasi, ekonomi, dan ke- 
bijakan publik serta ilmu-ilmu sosial lainnya, Ediis I, Jakarta: Prenada Media.

Fathoni, A 2006, Metodologi penelitian dan teknik penyusunan skripsi, Jakarta: PT Rineka Cipta.

Garcia, M, dkk. 2014, 'You have what? personality! traits that predict leadership styles for elementary principals', The Journal of Psychology, 5, 204-212.

Kent, TW, dkk. 2010, 'Gender differences and transformational leadership behavior do both german men and women lead in the same way', International journal of leadership studies, 6 (1), 52-66.

Lehmann, R, dkk. 2013, 'Age and gender differences in motivational manifestations of the big five from age 16 to 60', Developmental Psychology, 49 (2), 365-383.

Mansour, F 2006, Analisis gender dan transformasi social, Yogyakarta: Pustaka Pelajar.

McCullough, DG 2014, 'When will women achieve gen der equality in leadership at work', The Guardian, 4 Juni, Diakses 30 Agustus 2014, <http:// www.theguardian.com/sustain ablebusiness/womenleadership-com panies-equality-jobs $>$.

Muhammad, FB 2010, 'Pengaruh gaya kepemimpinan terhadap kepuasan kerja dan kinerja dengan komitmen organisasi sebagai variabel intervening', Journal of Leadership, 1(1), 1-14.

Nuri, H dan Bhaskaroga, DB 2012, 'Gaya kepemimpinan laki-laki dan perempuan', Journal of Leadership, 22 (2), 135- 146 .

Obiwuru, TC, Okwu, AT, Akpa, V dan Nwankwere, IA 2011, 'Effect of leadership style on organizational performance: A survey of selected small scale enterprises in ikosiketu council development area of Lagos state, Nigeria', Australian Journal of Business and Management Research, 1 (7) 100-111.
Pervine, LA, Cervone, D dan John, OP 2005, Personality theory and research, Edisi ke-9, Amerika: Lehigh Press.

Robbins, SP 2005, Organizational behaviour, Edisi ke-11, New Jersey: Prentice-Hall.

Rolls, ET 2013, 'Limbic systems for emotion and for memory, but no single limbic systems', Medical Journal, 30 (1), 1-39.

Schwartz, SH dan Rubel, T 2005, 'Sex differences in value priorities: Crosscultural and multi method studies', $J_{O}$ urnal of Personality and Social Psychology, 89, 1010-1028.

Sieff, G dan Carstens, L 2006, 'The relationship between personality type and leadership focus', Journal of Human Resources Management, 4 (1), 52- 62.

Snaebjornsson, IM \& Edvardsson, IR 2012, 'Gender, nationality, and leadership style: A literature review', International Journal of Business and Management, 8 (1), 89-103.

Sudjiwanti, 2010, 'Pengaruh tipe kepribadian big five terhadap gaya kepemimpinan transformasional karyawan PT Arta Boga Cemerlang Surabaya', Journal of Leadership, 7, 642-652.

Tantri, W, Margono, S dan Muhammad, S 2011, Analisa pengaruh gender, gaya kepemimpinan dan budaya organisasi terhadap produktivitas sekolah dasar negeri di Kabupaten Sidoarjo', Journal of Applied Management, 9 (3), 970-979.

Toegel, G dan Barzoux, JL 2013, 'How personality plays a role in effective leadership', The Jakarta Post, 1 Juni, Diakses 31 Agustus 2014, < http://www.thejakartapost.com/news/2 013/06/01/how-personality-plays-arole-effective-leadership.html $>$.

Weisberg, YJ, DeYoung, CG dan Hirsh, JB 2011, 'Gender differences in personality across the ten aspects of the big five', Journal of Psychology, 2 (178), $1-11$. 